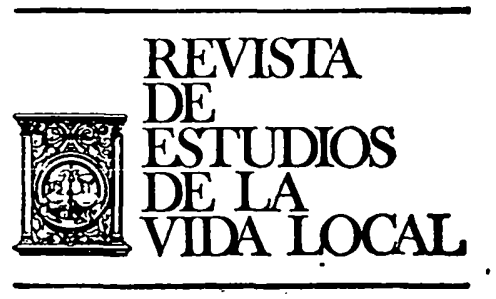

\title{
V. BIBLIOGRAFIA
}


REVL-1981, núm. 212. BIBLIOGRAFÍA

REVL-1981, núm. 212. BIBLIOGRAFÍA 
Alvarez Rico (Manuel), FERnandez Ordóñez (Rafael) y Alvarez Calvo (Antonio-José): Cánones de regulación y tarifas de riego motivados por obras hidráulicas. Madrid, 1981, 300 páginas.

Los autores, desde distintos horizontes, estudian en el presente trabajo un tema $\tan$ interesante, $y$ tan polémico en el orden práctico y doctrinal, como es el de los cánones y tarifas de riego. De esta manera, el tratamiento resulta más globalizado y completo, adquiriendo un especial valor en esta clase de cuestiones en las que se dan cita el Derecho, la Economía y las Ciencias Técnicas; y en las que, por lo mismo, hay que evitar el riesgo de planteamientos unilaterales y parcialistas.

En el libro que comentamos el aspecto jurídico es ciertamente el más importante, pero ello no es obstáculo para que los tres autores, especialistas muy cualificados cada uno en su rama respectiva, profundicen en puntos que requieren un soporte técnico y que ayudan a complementar la versión meramente legal y formalista del problema. De otro lado, el hecho de que estemos ante la primera monografía que se publica entre nosotros sobre la materia y que haya sido premiada con el segundo premio del Concurso centenario de la Ley de Aguas, convocado por el Ministerio de Obras Públicas y Urbanismo, avalan la actualidad de la misma; actualidad que no sólo se revela en la vertiente teó- rica, sino que también alcanza a la proyección práctica por cuanto que los autores son expertos y poseen una larga experiencia profesional.

A mayor abundamiento, el hecho de estar la materia objeto del libro necesitada de una actualización doctrinal que le abra nuevos caminos y, al mismo tiempo, cargada de vigencia con motivo de la promulgación de la Ley de 16 de octubre de 1980 sobre Régimen Económico del Trasvase TajoSegura, justifica y respalda, todavía más, la importancia de aquél, cara a la normativa futura y a la elaboración de nuevas disposiciones.

Seis capítulos conforman la obra, abordándose, respectivamente, las referencias de tipo histórico (capítulo $\mathrm{I}$ ), el régimen jurídico vigente (capítulo II), la potestad tarifaria de la Administración y las tarifas hidráulicas (capítulo III), la estructura de los cánones de regulación y tarifas de riego (capítulo IV), aprobación y gestión de los cánones de regulación y las tarifas de riego (capítulo $V$ ) y directrices para una nueva ordenación de cánones y tarifas (capítulo VI). Al final de cada capítulo se sitúan algunas notas bibliográficas $\mathrm{y}$, como cierre, aparece un anejo en el que se enumeran diversas normas de interés, así como algunas sentencias del Tribunal Supremo, debidamente ordenadas y clasificadas.

A la hora de formular una conclusión hay que felicitarse de que se haya publicado una obra como la acabada de comentar tanto por la asocia- 
ción de los enfoques teórico y práctico como por la anticipación de que han hecho gala los autores al adelantar soluciones de política hidráulica, muchas de las cuales se han recogido en la reciente Ley sobre Régimen Económico del Trasvase Tajo-Segura; sin olvidar la buena sistemática utilizada, ya que cada capítulo, en un apreciable ajuste de ideas y reflexiones, sirve de eslabón para la iniciación del siguiente.

Junto a estas luces no hay que ignorar las sombras propias de toda publicación colectiva e interdisciplinar, en la que suelen destacarse diferencias de tipo literario, además de las inevitables reiteraciones. En todo caso, estos defectos no empañan ni desvirtúan los méritos y calidades del libro aquí recensionado.

Vicente-M." González-Haba Guisado

Caplán (Benedicto), Llamas (ErnestoRaúl) y MEEHAN (José-Héctor): Manual de Gobierno y Administración Municipal, Consejo Federal de Inversiones de la República Argentina, 1977, 324 páginas.

El Consejo Federal de Inversiones, publica esta obra con el denominado carácter de manual, para que sirva fundamentalmente a las autoridades y funcionarios provinciales y municipales de la Argentina, así como a los estudiosos de Derecho administrativo y municipal de todos los países, en su vertiente de Derecho comparado.

$\mathrm{El}$ indicado manual comprende siete partes que son las siguientes:

1." Introducción, 2.: Naturaleza, elementos y relaciones de los Municipios, 3.' Régimen normativo munici- pal, 4." Organización municipal, 5." Régimen económico-financiero municipal, 6. Régimen y administración del personal municipal y 7: Comunicaciones e informaciones municipales.

En la Introducción, se trata: primero de la institución municipal que se considera "célula básica" de la comunidad organizada que constituye el Estado, tiene a su cargo el gobierno y la administración de los asuntos, acciones, obras y servicios requeridos por los habitantes del territorio de su jurisdicción (departamento, ciudad, distrito, etc.), con lo cual se observa que el concepto de Municipio es, en lo territorial, más amplio que en España.

Se sigue con la posible evolución que los Municipios argentinos tendrán en el proceso de reorganización nacional, puesto que, como en otros países ocurre, en los Municipios argentinos se evidencian las deficiencias que afectan al Estado en todos sus niveles.

Como finalidades específicas de una renovación municipal en la $\mathrm{Re}$ pública Argentina, se pretende que los Municipios, cualquiera que fuere su nivel, funcionen como in mecanismo orientado por el poder político que, interpretando las necesidades $y$ aspiraciones de la comunidad, establezca las pautas de su comportamiento, aumentando su eficiencia y mejorando cualitativamente su estructura para que se convierta en el principal y más importante instrumento de ejecución del desarrollo planificado que se proponga cumplir el Gobierno Central.

En cuanto a la segunda parte, referente a la naturaleza, elementos y relaciones del Municipio argentino, se analizan las distintas posturas doctrinales, referidas a. los autores ar- 
gentinos: Villegas, Fiorini y Marienhoff que defienden la autonomía municipal, en tanto que otros, tales como Linares Quintana, Dana Montanoo, Niouchet y Kurn Villafañe mantienen el principio de su dependencia estricta del Poder federal.

Respecto a los elementos del Municipio se contempla en principio el elemento humano, señalando, por ejemplo, la cantidad mínima de habitantes que se establecen a nivel provincial, cuyo dato pasa a ser el indicador básico para que las agrupaciones humanas puedan constituirse en Municipios.

El segundo elemento es el territorial, en el que se analiza el sistema radical de los Municipios establecido en la Argentina, ya que en la misma, pueden planificar distinguiendo las áreas urbanas, las urbanizables y las rurales, sin tener presente el factor histórico que condiciona tanto en Europa.

También se establecen los criterios de zonificación del territorio municipal, para lo cual, procede ordenar el uso del suelo según el destino de los asentamientos (residenciales, comerciales, industriales, rurales, etc.). Asimismo se analiza el Municipio en su entorno regional, estudiando la polarización respecto a los centros urbanos más importantes.

El tercer elemento gubernamental u organizativo según Mouchet, antes citado, dice que "si se cree que el Municipio debe ser un órgano de la soberanía popular debe admitirse que pueda actuar como órgano político, si bien dentro de su esfera propia».

A continuación se estudia las relaciones del Municipio tanto con otros como con las Provincias y la planificación nacional.

Respecto a la tercera parte, referente al régimen normativo munici- pal, se hace una completa referencia, tanto a las normas de rango superior, como son la Constitución Nacional, el Código Civil, las Constituciones provinciales y las Leyes Orgánicas municipales. Seguidamente, se trata de la legislación municipal interna, relativa a su organización y procedimiento administrativo, su personal, la gestión financiera municipal, los contratos administrativos municipales y la prestación de servicios municipales, tanto internos (Administración general) como externos (urbanismo, tráfico, higiene pública, etc.), para conseguir una racionalización normativa, que se estima necesaria, del régimen municipal.

En relación con la organización municipal, cuarta parte del manual, se refiere tanto a las competencias sustantivas, que son fundamentalmente las políticas, sociales, econó micas y urbanísticas, así como las competencias administrativas sobre presupuesto y fondos, personal, contabilidad y estadísticas. También se analizan las competencias concurrentes con respecto a la Nación y la Provincia, y las delegadas a las Municipalidades por las anteriormente citadas.

Respecto a los órganos y organismos municipales, en los Municipios argentinos el órgano determinativo, de elección popular, tiene diversas denominaciones, tales como: Concejo deliberante, Sala de representantes, Junta de fomento, Junta de centro rural, etc., así como un órgano ejecutivo generalmente a cargo de un Intendente municipal o Presidente de la Municipalidad, secundado por secretarios y funcionarios que él mismo designa.

Los organismos de acción sustantiva, cuyos objetivos se derivan de su propia denominación, son fundamen- 
talmente: la Secretaría de gobierno y bienestar económico social, la Secretaría de obras y servicios y la Oficina de planificación y programación presupuestaria.

En la quinta parte, relativa al régimen económico-financiero municipal, se estudia pormenorizadamente el régimen de la hacienda municipal sometida a normas generales, salvo que exista un régimen específico de carta municipal A continuación se trata de la planificación y presupuesto, afirmándose que no existe ningún Municipio sin presupuesto, pero en muy pocas Municipalidades existe planificación, aunque paulatinamente se va ampliando la misma.

Respecto a los recursos municipales, se arbitran los normales: de ingresos corrientes e ingresos de capital, diversificados en las distintas figuras impositivas de: tasas, impuestos y contribución especial de mejoras, así como ingresos con afectación a programas de desarrollo de la comunidad.

También se da entrada a los conceptos de presupuesto moderno, tates como la clasificación económica, institucional, funcional, por programas y por objeto del gasto, así como la ejecución y control financiero y contable del presupuesto, la evaluación de los resultados de costos y rendimientos, el tratamiento de los bienes de dominio municipal y las normas de contratación y concesión.

En la sexta parte, referente a los recursos humanos, es decir, el régimen y administración del personal municipal, se trata fundamentalmente de clasificarlo en: profesional o funcionario, técnico, docente, obrero y de maestranza y, finalmente, de servicio; especificando el conjunto de derechos y deberes de las personas que siguen la carrera municipal, así como sus ascensos, promociones y el régimen disciplinario.

Respecto a la última parte, sobre comunicaciones e informaciones municipales, versa sobre el procedimiento en sus fases de: recepción y registro, trámite y despacho, decisiones y su comunicación y difusión y el análisis de la estadística municipal, que analiza las series estadísticas relativas a la evolución demográfica, económica, social, sanitaria, cultural y urbanística y la cuantificación de las obras, servicios y finanzas municipales.

El manual se completa con unas conclusiones sobre las Jornadas de Administración Municipal de La Rioja (Argentina), que tienden a potenciar e impulsar la actuación municipal en la Argentina.

Concluye con un apéndice biblio gráfico, tanto de normas nacionales, provinciales y municipales, como de libros y publicaciones, fundamentalmente de origen argentino.

En un juicio evaluatorio de la obra publicada por el Consejo Federal de Inversiones de la Argentina, se aprecia que se trata de un intento, logrado, de recopilar - de una manera útil y de inmediata aplicación - todo el conjunto de normas jurídicas y técnicas de la Administración municipal para conseguir un perfeccionamiento de las estructuras, régimen y sistemas de gobierno y administración municipal, acorde con los objetivos gubernamentales de reorganización del Estado argentino. Al mismo tiempo, y desde un enfoque general, constituye una obra que es indispensable como punto de referencia del estudio comparado de las Municipalidades argentinas con las de otros países, y por supuesto de España. Además, no es solamente una obra de escueto contenido jurídico, sino que presenta 
notables aspectos de administración, organización y funcionamiento municipal muy subrayables.

\section{Manuel Domínguez Alonso}

Dtez (Florentino-Agustín): Romance de Madrid. Concejo abierto. Madrid, Biblioteca Certamen, 1981, 130 págs.

No estábamos muy sobrados de libros que, como el de FlorentinoAgustín Díez, Romance de Madrid. Concejo abierto, nos introdujeran en la historia del Municipio español de la mano de la lírica, uporque España es el país del Romanceron, y como base el Fuero de Madrid de 1202, conteniendo numerosas e importantes referencias de otros Fueros como el de León, el de Usagre y las Consuetudines ilerdenses.

En el Romance de Madrid no hay héroes singulares, porque todo el personaje y todo el protagonismo es del pueblo, son el pueblo mismo: aquella lejana vecindad madrileña de finales del siglo xiII que tan admirables grados de emancipación so cial alcanzara y que se reflejan aleccionadoramente en su Fuero o Carta concejil de 1202, Carta municipal o Ley foral que el pueblo elabora y se otorga a sí mismo.

Como primera motivación evoca en su libro el autor eun Madrid campesino, artesano también, casi aldeano, cabalgando sobre la historia y haciéndola, enraizado ya en su terruño sobre las ruinas de una plaza fuerte de vanguardia que alertaba las fiebres del moro de Toledo siempre temeroso del poder cristianon. El clima rural de Madrid se pinta maravillosamente, a la mano de Gómez Iglesias y Gerónimo de la Quintana, evocando a los habitantes de la villa aesparcidos por su exiguo alfoz, dedicados al cultivo de las viñas de la Fuente Castellana, al de las huertas de Atocha, de sus campos de trigo y cebada o las faenas del estío en el ejido de Barrionuevo o bien apacentando ganado en los sotos y pastizales de Migas Calientes...»

$\mathrm{Y}$ el río Manzanares que, al decir del Conde Juan de Rhebiner, embajador que fue del Emperador Rudolfo II de Alemania, «era el mejor río que había en toda Europa, porque se podía en coche y a caballo ir por medio de él tres o cuatro leguas sin peligro alguno, gozando de una y otra parte de amenos sotos y verdes alamedas, cuya frescura y el silencio de las aguas, con la suave armonía de las aves que en su espesura se aposentan...»

$\mathrm{Y}$ el otro gran elemento embellecedor de la campiña del viejo Madrid: las fuentes. Fuentes sin número y entre ellas las había de «agua preciosa y singular, como son las de Lavapiés y las de Leganitos. Pero además había otras muchas no menos excelentes, como, por ejemplo, las del Prado de San Jerónimo, las del Caño Dorado, del Ovillo y de la Sierpe; la muy conocida del Humilladero de Nuestra Señora de Atocha; fuentes del Peral y Fuentes de San Pedro; las de Caños Viejos, la del Angel de la Guarda, la del Sol en el camino de El Pardo y la Fuencastellana en el de Hortaleza, más otras y otras, más ricas todas en agua, de fama y de virtud». Y tras de esto, se recrea el autor con la poderosa sugestión del recorrido de aldeas y ciudades, topónimos y locativos de los parajes querenciosos que van poblando también los capítulos del Fuero. 
Y como símbolo, el glorioso patro nazgo de la Villa: San Isidro Labrador de tierra y cielo, y como ente vital, eje del pueblo, el vecino.

En la Carta concejil de Madrid el vecino es "valorado por su defensa $e$ integridad con que se le rodea y así se nos irá recordando: Que no se golpee a vecino o hijo de vecino, y no se haga con armas, instrumentos, palos ni piedras ni de puños ni a coces; que no le mesen la barba y pobre del que lo matare o lisiare, que nadie penetre con fuerza en casa de vecino, ni se la allane ni se la incendie... Se defenderá la paz y la seguridad del pueblo...» Arremete el Fuero contra lo que llama "verbos prohibidos», esto es, insultos, injurias, tales como «falso», «sodomita», "cornudo", "gafo»..., un conjunto de medidas que persiguen imponer un orden social y unas garantías de respeto, de paz y de justicia.

Finalmente, las vecindades, cuyo proceso «iba camino de ofrecer razón y fundamento al Rey Alfonso el Sabio, para dar, como lo hizo medio siglo después, aquella admirable definición de pueblo, válida para todo tiempo, Pueblo tanto quiere decir Ayuntamiento de gentes de todas maneras de aquella tierra do se alle. gan. $E$ desto no sale home ni muger, ni clérigo ni lego... (Part. I, Tít. II, Ley V)".

Tras de este recorrido, la evocación de el juglar: «El texto del Fuero de Madrid supone un público aficionado al espectáculo juglaresco». El juglar, especialmente poeta $y$ artista del pueblo, "divertía a todas las clases sociales y gozaba de gran predicamento y protección, porque con el solaz que impartía, el pueblo se demudaba de placentero descanso y los altos jerarcas se aserenaban su mente abrumada de preocupaciones $y$ fatiga».

Pero hay un motivo importante que ilumina todo el trabajo escrito de mano maestra, por FlorentinoAgustín Díez. Es, como decíamos al principio, el estudio y valoración de los viejos textos forales de los que dice: «estos textos, como el de Madrid, nos hablan y nos enseñan, cómo el pueblo, pueblo-burgo, pueblo. aldea, pueblo pueblo, va elaborando su Derecho y con él sus instituciones, con éstas, su justicia y, en fin, con su justicia, su convivencia, su paz y su libertad Al obrar así, el pueblo. crea, como crea el artista, como crea el poeta -también se hablará del pueblo poeta-, crea formas de vida, cauces de libertad, reivindicando su señorío social que únicamente es auténtico cuando se trata del propio. señorío del pueblo, el que interpreta perspicaz, sabia y prudentemente su: Concejo, es decir, la vecindad arraigada, instituida y aforada...»

En el capítulo «sobre quién y cómo se da el Fuero", el autor estudia el proceso en que las antiguas vecindades se reafirman en su condición de Concejos autónomos. Examina las formas de otorgamiento de los Fueros: fuero real o Concejo de realengo, fuero de pacto, convenio $o$. concordia, asunción del fuero por propia voluntad y cuando el Concejo. legisla y se da su propio fuero, subrayando el alto nivel de autonomía municipal con que se produce y promulga el de Madrid, comparándolo. con otros fueros que constituyen el Concejo tipo de la Edad Media, «una edad de muy lento, fatigoso pero. enorme laboreo; tiempos, energías yfuegos de un crisol donde se depu- 
ran virtudes, valores $\mathrm{y}$ arquetipos sociales: serán el caudillo o el caballero, serán el monje o el santo, será el hombre bueno -los boni hómines-, será, sobre todos los valores sociales y populares, el vecino $\mathrm{y}$, con él y por él, el pueblo; será, en fin, el Concejo, faz del pueblo y cuna del ciudadano libre».

El libro contiene un segunda parte dedicada al romance propiamente dicho, formulando, como inicio de la misma, un glosario de voces anti:guas y «algunos de los más significativos nombres que en el Romance de Madrid de los Fueros aparecen y .deben conservar su virtud y su nombre de veraces testigos».

Queremos -dice el autor- evocar, fieles al claro y noble linaje literario del romance, al lejano pueblo de Ma-drid, héroe colectivo del silencio y del sudor humildes, creador, sin embargo, de puras instituciones sociales, coautor del Derecho y de la Historia.

Componen el Romance, además del glosario, ocho cantos: el Libro, el Sello, el Alfoz, el Pueblo, el Concejo, la Justicia, el Legado y Que Santisidro... De éste extraemos - para terminar nuestro apunte- los siguientes versos:

"Aqui termina el romance de Madrid Concejo Abierto.

Tiempos de gran facendera fueron los tiempos aquellos, fiebres amuchiguadoras de fundación y renuevo. Alli se engendro la estirpe con buen arraigo, alli el tiempo de un convivir ajustado en libertad... Nació el pueblo...”

\section{Juan González Escribano}

González Pérez (Jesús): Comentarios a la Ley del Suelo, 4." edición, con la colaboración de Pedro GonZález SALINAS. Madrid, Editorial CIVITAS, 1981, 2 vols.

Nos hallamos frente a una nueva edición de los ya clásicos "Comentarios a la Ley del Suelo" de Jesús González Pérez, en los que, artículo por artículo, se analizan todos los problemas que la Ley del Suelo plantea.

La primera edición comentaba la Ley de 12 de mayo de 1956; la segunda (publicada en 1976) y la tercera (publicada en 1977) comentaban ya el articulado del Texto refundido (por Decreto de 9 de abril de 1976) de la Ley de 1956 y de la de 2 de mayo de 1975, que modificó profundamente la de 1956. En la cuarta los comentarios se estructuran, asimismo, en torno a los artículos del citado Texto refundido.

Sin embargo, y pese a lo que pudiera, a primera vista, sugerir la rápida sucesión de tres ediciones en menos de cinco años, lo cierto es que la que ahora comentamos, lejos de ser una mera reedición de la tercera, es en realidad una obra totalmente distinta de ésta, totalmente reestructurada y enormemente ampliada.

Hay que tener en cuenta que, poco después de la publicación de la tercera edición, se publicaron tres nuevos Reglamentos (el de Planeamiento, aprobado por Real Decreto 2159/1978, de 23 de junio; el de Disciplina Urbanística, aprobado por Real Decreto $2187 / 1978$, de 23 de junio, y el de Gestión Urbanística, aprobado por Real Decreto $3288 / 1978$, de 25 de agosto) "para el desarrollo y aplicación de la Ley sobre Régimen del Suelo y Ordenación Urbana»; que por Orden de 20 de diciembre de 1978 se aprobaron las 
Ordenanzas fiscales reguladoras de los impuestos municipales, sobre solares y sobre incremento del valor de los terrenos; que a partir de 1978, y a lo largo de los años siguientes, se ha sucedido una serie -que aún hoy prosigue- de Reales Decretos que transfieren a diversos Entes preautonómicos o a Comunidades autónomas ya constituidas de acuerdo con la Constitución diversas competencias en materias urbanísticas; que desde 1978 hasta hoy se suceden también normas que modifican la organización del Ministerio de Obras Públicas y Urbanismo, de la Comisión Central de Urbanismo y de diversas Comisiones provinciales de Urbanismo; que la doctrina de los autores y la jurisprudencia del Tribunal Supremo, que hasta 1977 apenas habían encontrado ocasión de interpretar los preceptos de la Ley de Reforma de 1975, desde un punto de vista operativo, la han hallado ya repetidamente entre 1977 y 1981; que -en fin, y por no alargar más esta ya extensa cita- la propia entrada en vigor de la Constitución, que expresamente se refiere a la acción urbanística, ha tenido que incidir profundamente -aunque desde luego sea aún pronto para calibrar exactamente el alcance práctico de di- cha incidencia - en la normativa precedente.

Estas circunstancias han determinado que -como ya hemos adelantadoJesús González Pérez nos ofrezca ahora una obra totalmente nueva, muy ampliada y totalmente reestructurada. Al comentar cada uno de los artículos del Texto refundido se tienen en cuenta las nuevas normas reglamentarias dictadas para el desarrollo y aplicación de la Ley y las nuevas normas orgánicas que las afectan; en cada artículo, también, se recoge toda la doctrina y toda la jurisprudencia que desde 1977 hasta 1981 han sido publicadas. Y en cada caso, el autor no se limita a transcribir las normas, doctrinas y sentencias; las analiza, las critica y ofrece su propia visión del problema, tanto desde el punto de vista doctrinal como del pragmático.

No nos hallamos, pues, ante la simple reedición de una obra ya publicada. En realidad, es ésta una obra nueva, ampliada y reestructurada, cuyo manejo es indispensable para quien, por razones pragmáticas o por puro afán de aprendizaje, intente adentrarse en la ya frondosa selva de nuestro Derecho urbanístico.

Salvador Ortolá Navarro 